Anales de Geografía de la Universidad Complutense ISSN: 0211-9803

http://dx.doi.org/10.5209/AGUC.55955

\title{
Transformaciones espaciotemporales de la Reserva Natural Laguna de Sonso (Colombia) desde mediados del siglo XX a principios del siglo $\mathrm{XXI}^{1}$
}

\author{
Oscar Buitrago Bermúdez $z^{2}$ Marco Antonio Aguirre ${ }^{3}$ \\ Recibido: 12 demayo del 2016 / Enviado a evaluar: 22 de julio del 2016/ Aceptado: 16 de diciembre del 2016
}

Resumen. El actual modelo económico capitalista suscita cada vez más el acaparamiento de recursos a nivel global, entre ellos, suelo, bosque y agua. En ese contexto, en los últimos setenta años las élites económicas respaldadas a través de políticas de desarrollo, han promovido la expansión del monocultivo de caña de azúcar en el departamento del Valle del Cauca y otras regiones de Colombia. Ante tal situación, los humedales como ecosistemas estratégicos por su contenido en fauna y flora, riqueza paisajística y fuente de sustento de comunidades locales, son vulnerados ante la expansión del cultivo. Para entender este proceso, primero se realiza un análisis multitemporal de coberturas del suelo al complejo de humedales que integran la Reserva Natural Laguna de Sonso (desde mediados del siglo XX hasta principios del siglo XXI), y segundo, incorporaran técnicas cualitativas de investigación. Los resultados permiten avanzar en conocimientos locales para la defensa y conservación de humedales, así como su planificación y manejo.

Palabras clave: Desarrollo; humedales; análisis multitemporal; Reserva Natural Laguna de Sonso.

\section{[en] Spatiotemporal transformations of the Laguna de Sonso Nature Reserve (Colombia) mid-twentieth century to the early-twenty first century}

\footnotetext{
Abstract. The current capitalist economic model is increasingly taking hold of natural resources at the global level, including soil, forests and water. In this context, during the last seventy years, the economic elites backed by development policies, have promoted the expansion of the sugar cane monoculture in the department of Valle del Cauca and other regions of Colombia. Thus, wetlands - strategic ecosystems

1 Este artículo hace parte de los resultados del proyecto de investigación "Los humedales vallecaucanos: escenario natural de cambios históricos de ocupación y transformación” el cual fue financiado y auspiciado por la Vicerrectoría de Investigaciones de la Universidad del Valle. Como objetivo general del mismo, se contempló aquellos factores directamente relacionados con las transformaciones históricas más representativas ocurridas en humedales relacionadas con los ámbitos socioeconómico, geográfico y ecológico.

2 Departamento de Geografía. Universidade del Valle (Colombia)

E-mail: oscar.buitrago@correounivalle.edu.co

3 Departamento de Geografía. Universidade del Valle (Colombia)

E-mail: marco.aguirre@correounivalle.edu.co
} 
due to the richness of their fauna and flora, landscape beauty, and capacity to serve as a source of livelihood for local communities - are threatened for the expansion of the crop. To understand this process, firstly, we performed a multi-temporal analysis of the land covers which comprise the complex wetland system of the Laguna de Sonso Nature Reserve (from mid-twentieth century to the early twentyfirst century). And, secondly, we incorporated qualitative research techniques. Results allow local knowledge to advance for the protection and conservation of wetlands, as well as in their planning and management.

Keywords: Development; wetlands; multi-temporal analysis; Natural Reserve Sonso Lagoon.

[fr] Transformations de la Réserve Naturelle Lagune de Sonso (Colombie) de la moitié du $\mathrm{XX}^{\mathrm{ème}}$ siècle au début du $\mathrm{XXI}^{\mathrm{ème}}$ : une analyse géographique en vue de sa planification et de de sa gestion

Résumé. Le modèle économique capitaliste actuel suscite de plus en plus et à une échelle mondiale l'appât des ressources, telles que le sol, la forêt et l'eau. C'est dans ce contexte que depuis soixante-dix ans les élites économiques appuyées par des politiques de développement développèrent l'expansion exclusive de la culture de la canne à sucre dans le département du Valle del Cauca ainsi que dans d'autres régions colombiennes. Dans ce contexte, les zones de marécage qui sont des écosystèmes stratégiques du point de vue de leur faune et de leur flore, de la diversité paysagère, en plus d'être des sources de revenue pour les communautés locales, sont fragilisées par cette culture intense. Afin de comprendre au mieux ce processus, on effectuera une analyse multi temporelle de la couche superficielle du sol, de la moitié du XXème siècle au début du XXIème, de l'ensemble des marécages qui conforment la Réserve Naturelle de la Lagune de Sonso; on incorporera, ensuite, à cette analyse des techniques qualitatives de recherche. Les résultats obtenus permettent d'avancer dans les connaissances locales en vue de la défense et la conservation des zones de marécages, de leur planification et de leur gestion.

Mots clés: Développement; marécages; analyse multi temporelle; Réserve Naturelle de la Lagune de Sonso.

Cómo citar. Buitrago Bermúdez, O. y Aguirre, M.A. (2016): Transformaciones espaciotemporales de la Reserva Natural Laguna de Sonso (Colombia) desde mediados del sigo XX a principios del siglo XXI. Anales de Geografía de la Universidad Complutense, 37(1), 43-65.

Sumario. 1. Introducción. 2. Humedales de estudio. 3. Metodología. 4. Resultados. 5. Contrastes entre los cambios presentes en la cartografía y las voces de algunos agentes sociales comunitarios. 6. Conclusiones. 7. Referencias bibliográficas. 8. Fuentes electrónicas.

\section{Introducción}

En los últimos cincuenta años los humedales del departamento del Valle del Cauca han experimentado cambios significativos asociados a pérdida en espejo de agua lagunar, detrimento en fauna y flora, así como notables consecuencias sociales, culturales y ambientales, derivadas, en gran parte, por los intereses de unos pocos agentes sociales capitalistas y a través de políticas desarrollistas. En respuesta a ello, las distintas comunidades que por décadas han vivido y ejercido sus prácticas cotidianas en cercanías a estos ecosistemas, se han visto obligadas a desplazarse y en ocasiones a ceder sus propiedades por precios irrisorios. Dichos cambios han estado ligados a nuevos usos del suelo como producto de las formas de concebir el espacio 
por distintos agentes sociales, entre ellos, las élites vallecaucanas, quienes lograron materializar sus proyectos desarrollistas bajo el marco de políticas nacionales e internacionales, las cuales propiciaron en gran parte la conformación del clúster de la caña de azúcar en la región, cubriendo de esta forma, buena parte los suelos de la planicie aluvial del río Cauca. En ese contexto, el Departamento dejó de ser una de las despensas agrícolas más importantes de la región para inicios del siglo XX (Perafán, 2005) para convertirse en escenario de expansión de actividades agropecuarias como la caña de azúcar.

Con respecto a lo anterior, Perafán (2005: 5) comenta que a partir de la década de 1930 del siglo XX, por acciones políticas de gobiernos de turno, se concibe una nueva forma de producción del espacio sustentada en el "desarrollo económico de la región". Es el comienzo de uno de los periodos caracterizado por la incursión de distintas misiones internacionales con fines desarrollistas en la región, de las cuales, cabe resaltar la misión puertorriqueña liderada por Charles Chardón; visita que concluyó en la importancia de potenciar, entre otros, el monocultivo de la caña de azúcar para sacar provecho de las excelentes condiciones ambientales, hídricas y geográficas de la parte plana del departamento del Valle del Cauca.

A finales de la década de 1950 se evidencia en el departamento del Valle del Cauca el auge de la producción de caña de azúcar, potenciada por las buenas condiciones en infraestructura vial que implicaba todo un entramado regional; además, del crecimiento de los distintos ingenios y la adquisición masiva de tierras, a través de medios legales e ilegales para la producción. Este universo de posibilidades se sumaba al bloqueo económico realizado por los Estados Unidos a Cuba, quien para la época era uno de los productores de caña de azúcar más importantes a nivel mundial. Tal acción geopolítica, derivó en la búsqueda de nuevos puntos geográficos para llevar a cabo la implementación de grandes sistemas agroindustriales, situación que aceleró, entre otras cosas, la expansión del cultivo de la caña a expensas de la sustitución de prácticas económicas productivas y la pérdida acelerada de bosques y cuerpos de agua.

Para llevar a cabo tal impronta, se requería buscar soluciones que menguaran los desastres ocasionados por las inundaciones del río Cauca a lo largo del Departamento, así como controlar los constantes desbordamientos y avalanchas generados por sus afluentes, los cuales producían pérdidas económicas en los cultivos. En este contexto, se concibe la creación de la Corporación Autónoma Regional del Cauca -CVC- en Octubre de 1954, con un objetivo en común, promover el desarrollo integral del Valle del Alto Cauca "sustentado en la producción agropecuaria, aprovechando, para ello, la fertilidad de los suelos" (Zuluaga, et al, 2012: 145).

Actualmente, la expansión del cultivo de la caña de azúcar se evidencia en un aumento importante en la cantidad de hectáreas sembradas. Para el año de 1960 había 61.600 hectáreas sembradas en caña de azúcar sobre la planicie aluvial del río Cauca (Perafán, 2005: 9), mientras que para el año 2007, se registró un total de 200.000 hectáreas sembradas (Corporación Autónoma Regional del Valle del Cauca -CVC-, 2007: 22), cifras que indican un aumento aproximado en cuatro veces su área inicial, en menos de cinco décadas. 
En la Figura 1 se observa el incremento en áreas destinadas para la siembra de caña de azúcar en el valle aluvial del río Cauca entre 1986 y 2014. En color verde se resalta la cobertura $\mathrm{C} 1$, que corresponde a áreas destinadas a Bosques, y en amarillo, la cobertura $\mathrm{C} 2$ correspondiente a áreas Misceláneas (suelo desnudo, pastos, cultivos y áreas construidas).

Figura 1. Expansión de las áreas destinadas a la siembra de caña de azúcar en el valle geográfico del río Cauca, 1986 - 2014

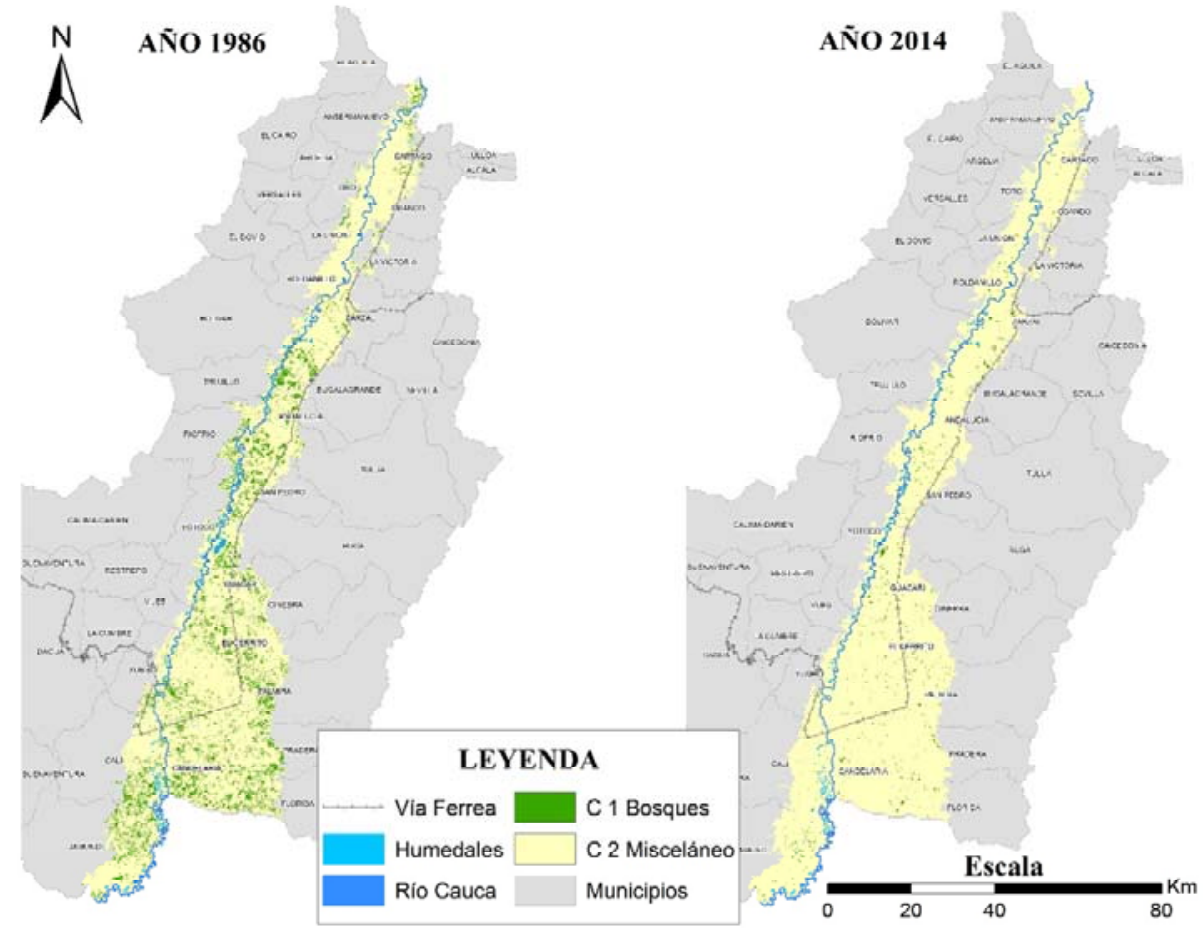

Frente: Elaboración propia

Estas coberturas evidencian los cambios ocurridos entre los años de 1986 y 2014 con respecto a áreas intervenidas antrópicamente a través de prácticas materiales sustentadas, en gran medida, por la expansión de la agroindustria cañera, versus coberturas de bosque que han ido retrocediendo en función de la expansión agropecuaria, así como de las áreas destinadas a humedales. Es importante destacar el retroceso de la cobertura C1 para el año de 1986 con respecto al año 2014, producto de la acción humana, a partir de la adecuación de buena parte de los suelos presentes en la planicie aluvial del río Cauca, así como la expansión de áreas construidas. 
Es precisamente en las postrimerías del siglo XX cuando inicia el auge y crecimiento del desarrollo de la agroindustria en el Territorio Nacional, para abastecer en términos energéticos la demanda mundial y nacional por nuevos combustibles, basados en el paradigma del desarrollo sustentable y en pro de contribuir al mejoramiento de las condiciones climáticas a escala global y local. En respuesta a lo anterior, los distintos gobiernos de turno empiezan a orientar sus políticas de desarrollo hacia la promoción y ejecución de proyectos sustentados en la agroindustria para agro-combustibles a nivel nacional, y a garantizar con incentivos económicos a quienes propicien tal ejecución (Ley 1151, 2007: 222; Departamento Nacional de Planeación, 2011: 611 - 614; Ley 939, 2004: 1).

Los humedales como ecosistemas son producto de la estructura meándrica del río Cauca, propia de una planicie aluvial, cuya dinámica va formado con el tiempo distintos cuerpos de agua, ya sean cauces abandonados llamados madreviejas (Patiño, 1998) y complejos cenagosos o cuerpos lagunares derivados de las condiciones morfodinámicas de la planicie aluvial. Según Segrelles y Vásquez (2012: 364) buena parte de los humedales del Valle del Cauca corresponden a "cuerpos de agua formados por estrangulamiento debido a la sinuosidad del río Cauca y las características geomorfológicas de la planicie aluvial, [...] que dan fe del antiguo cauce del segundo río más importante del país".

Ante este panorama de expansión de los agronegocios, los ecosistemas de humedales se ven en grave riesgo de desaparecer por efecto de la acción humana. Así mismo, la sociedad se ve directamente afectada cuando no se les da uso adecuado y razonable (Castañeda, 2012: 20). En ese sentido, resulta importante comprender desde perspectivas sociocríticas la manera en la cual, las actividades humanas han incidido en la transformación y deterioro de buena parte de los ecosistemas de humedales en el Valle del Cauca con el ánimo de contribuir en herramientas y estrategias que propicien su conservación y planificación. Con respecto a lo anterior, este artículo pretende realizar un análisis multitemporal de algunas coberturas del suelo de la Reserva Natural Laguna de Sonso e identificar causas asociadas a las transformaciones presentes en las coberturas en un periodo de tiempo de sesenta años.

Para ello, se parte de los Sistemas de Información Geográficos (SIG) entendiendo estos como el "conjunto de instrumentos y metodologías que permiten capturar, almacenar, analizar, transformar, relacionar y presentar información territorial y espacial georeferenciada del mundo real" (González et al., 2014: 5), que por sí solos pueden ser considerados como un potente sistema de gestión de bases de datos para estudios de carácter espacio-temporales, sociales, ambiental, entre otros. Los SIG por sí solos representan una herramienta potente y útil en el análisis espacial, pero al combinarlos con técnicas de investigación cualitativas y métodos mixtos representan mayor utilidad en la interpretación y comprensión de dichos fenómenos y cambios espaciotemporales. Atributo que permite a la geografía la implementación de "conocimientos y habilidades geográficas para la resolución de problemas sociales, económicos y ambientales, aspecto que se sustenta actualmente en las metodologías y técnicas (cualitativas y cuantitativas) del análisis espacial que pueden ser llevadas a 
cabo a través del uso de los SIG al servicio de procesos en la toma de decisiones en materia de planificación y ordenamiento territorial" (Fuenzalida et al., 2015: 1).

\section{Humedales de estudio}

Los humedales a trabajar en este artículo corresponden a las madreviejas La Marina, el Burro y Laguna de Sonso, los cuales se localizan en el centro del departamento del Valle del Cauca, en jurisdicción del municipio de Gualdajara de Buga, y cerca a los municipios de Yotoco y Guacarí. Estos cuerpos de agua conforman la Reserva Natural Laguna de Sonso (Corporación Autónoma Regional del Valle del Cauca -CVC-, 2009: 175). La Reserva tiene una extensión aproximada de 745 ha., rodeadas por 1.300 ha., de zona amortiguadora (Ver Figura 2). Su altura promedio sobre el nivel del mar es de 940 m, y su temperatura media es de $24^{\circ} \mathrm{C}$ (Álvarez, 1999: 15).

Figura 2. Localización Reserva Natural Laguna de Sonso

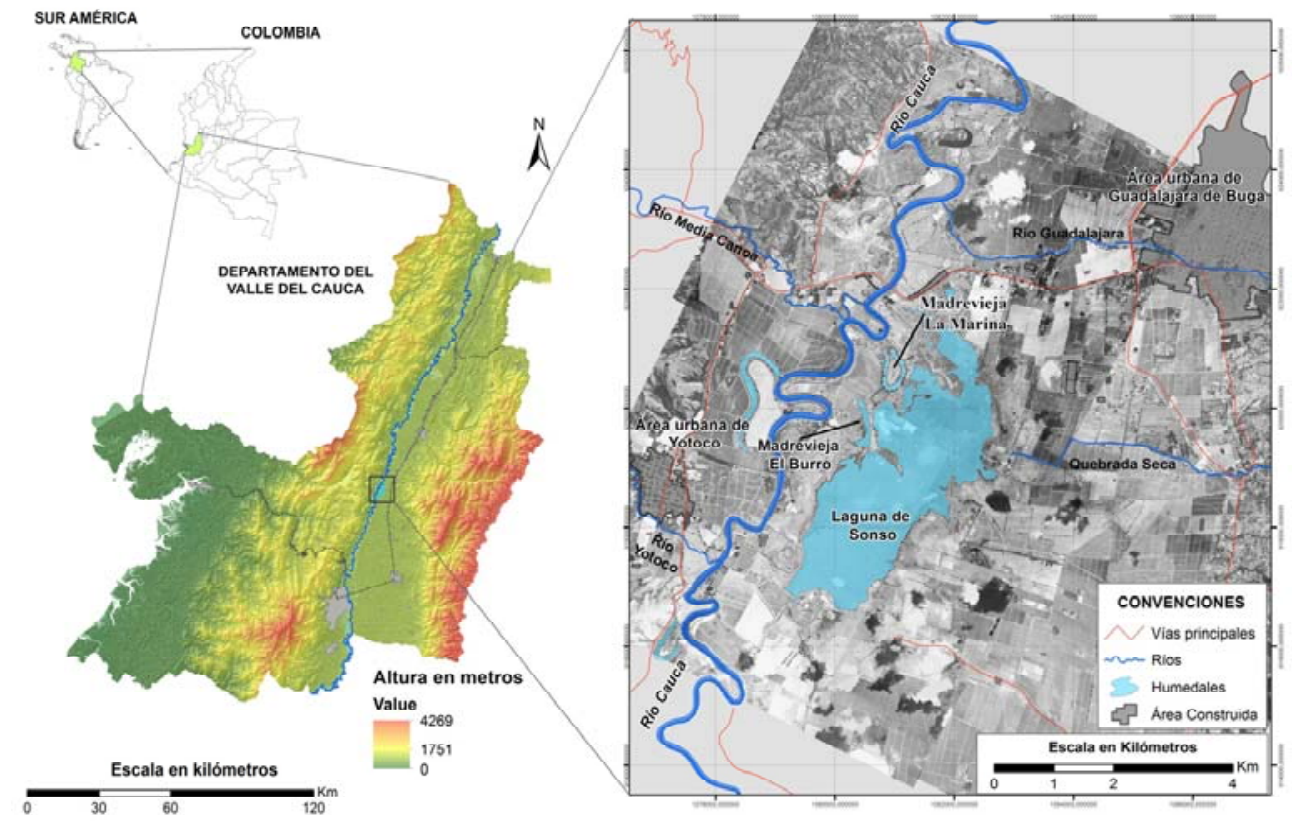

Fuente: Elaboración propia a partir de fotografías áreas suministradas por la Corporación Autónoma Regional del Valle del Cauca-CVC- 
El humedal Laguna de Sonso se denomina ecosistema natural, lentico lacustre; considerado como el último ecosistema de aguas loticas del departamento del Valle del Cauca (CVC, 2007: 1), y concebido como ecosistema de importancia mundial según la Convención Ramsar de 1971 (Secretaría de la Convención de Ramsar, 2013), además, fue "catalogado como Reserva Natural desde octubre de 1978 por parte de la Corporación Autónoma Regional del Valle del Cauca (CVC), siendo sometida a un reglamento especial para el uso del agua, el empleo del suelo y el control del espacio aéreo" fruto de su gran valor cultural y ecológico (Segrelles y Vásquez, 2012: 364). La Marina y El Burro son ecosistemas lentico palustres, correspondientes a madreviejas formadas por la dinámica meándrica del río Cauca a su paso por el municipio de Gualadajara de Buga.

Actualmente, el humedal Laguna de Sonso colinda con 23 predios: 10 de ellos, dedicados a la ganadería; 8 , sembrados en caña; y 4 predios, destinados a la siembra de cultivos transitorios y pancoger, representados en cultivos de maíz, millo y zapallo. Los humedales de la Reserva Natural Laguna de Sonso limitan geográficamente con los caseríos de Puerto Bertín, El Porvenir y Villa Lobín, y colindan con las haciendas Bello Horizonte y La Isabela, además, del caserío Guayabito. Destacan los agentes sociales de Puerto Bertín, quienes históricamente, se han dedicado a la pesca artesanal y deportiva; a la extracción de material de arrastre (arena) del río Cauca como una actividad de subsistencia, y a la prestación de servicios laborales como jornaleros en haciendas cercanas. Por otro lado, en la Reserva Natural Laguna de Sonso, se han desarrollado actividades en relación al ecosistema que involucran el avistamiento de aves, ecoturismo y prácticas de esparcimiento. En las Figuras 3, 4 y 5 se observan los respectivos humedales.

Figura 3. Vista panorámica del Humedal Laguna de Sonso

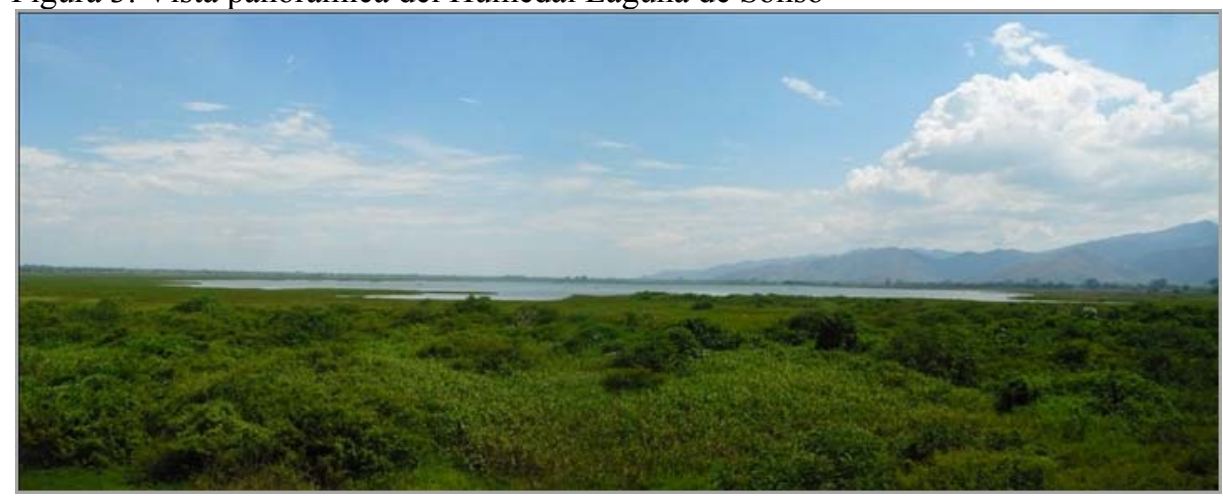

Fuente: Aguirre y Perdomo (2015: 63) 
Figura 4. Madrevieja el Burro ${ }^{4}$.

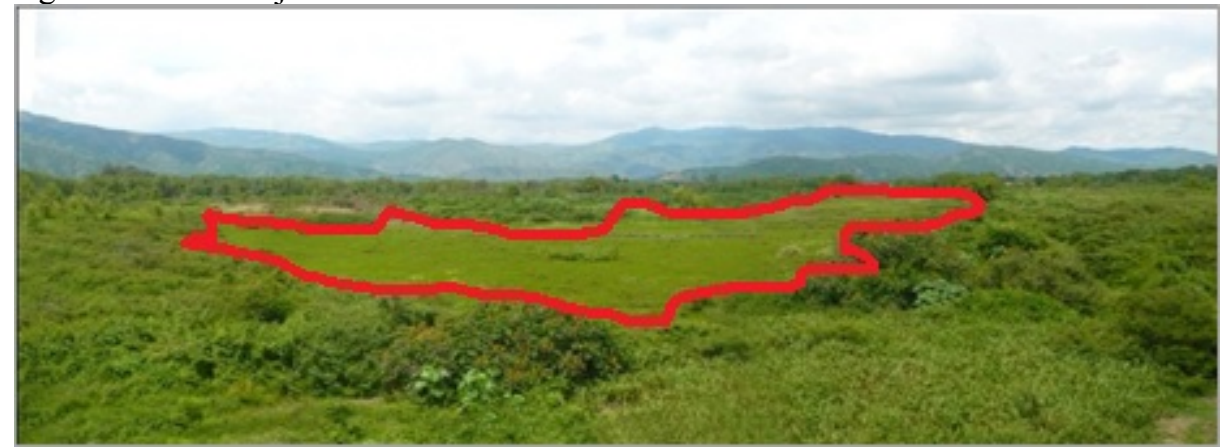

Fuente: Aguirre y Perdomo (2015: 63)

Figura 5. Madrevieja la Marina ${ }^{5}$

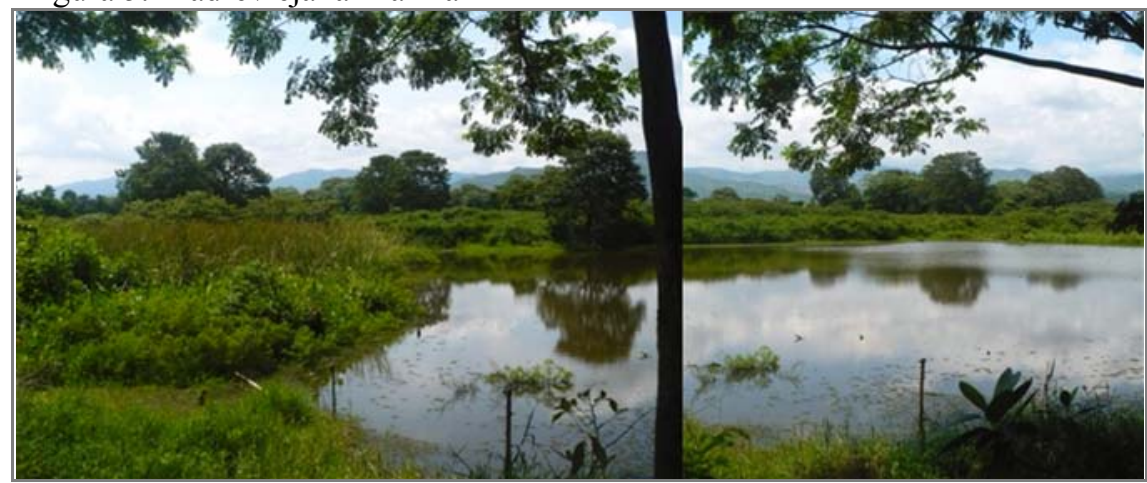

Fuente: Aguirre y Perdomo (2015: 64)

Recientemente, el Humedal Laguna de Sonso fue intervenido por agentes cañeros, vecinos de la Reserva, quienes a finales de diciembre del año 2015, encaminaron acciones destinadas a drenar parte del humedal, con el fin de expandir sus áreas de cultivo. La denuncia se realizó a través de distintos medios de comunicación, con alcances sociales y científicos, por la magnitud del daño ambiental y social ocasionado, puesto que se bloqueó el principal canal de comunicación del humedal con el río Cauca, y se construyó un nuevo canal el cual depositaba el agua del interior del humedal a las áreas de cultivo. En uno de los fragmentos titulados por el Diario el Espectador se evidencia lo siguiente "A lo largo de tres semanas, muchos pobladores

$4 \quad$ El polígono representa el área actual que ocupa este humedal; en términos de paisaje se observa vegetación acuática enraizada sobre el espejo de agua del humedal con mayor presencia de pastos, y su avanzado estado de sedimentación.

5 Este humedal se encuentra actualmente intervenido por la Corporación Autónoma Regional del Valle del Cauca CVC- para usos de Investigación y avistamiento de aves. 
y pescadores de los municipios de Buga, Yotoco y Guacarí vieron cómo, poco a poco, con la ayuda de buldóceres y retroexcavadoras, un pedazo de la laguna estaba desapareciendo" (Diario el Espectador, Edición 20 de enero de 2016). Este hecho deja en evidencia, por un lado, la vulnerabilidad del Estado representada a través de las autoridades ambientales frente a las formas de poder de algunos agentes sociales capitalistas en la Región, y por otro, resalta la problemática expuesta anteriormente en el documento.

En ese contexto, el paisaje de estos humedales se encuentra dominado por dos atributos: primero, los diferentes tipos de ganadería que se desarrollan en áreas inundables y cerca de los humedales; y segundo, por la presencia de actividades agrícolas asociadas al monocultivo de la caña de azúcar en tierra firme y próximos a los ecosistemas y la implementación de cultivos transitorios a pequeña escala.

Hoy en día, cerca de la Reserva se localizan empresas de tipo agroindustrial que desarrollan actividades destinadas a: avicultura; producción de abonos orgánicos; procesamiento, preparación y conservación de carnes; empaques de harina y vidrio; centros educativos; hoteles; y centros de recreación (Aguirre y Perdomo, 2015: 65). Además, se evidencia la extracción de arena del el río Cauca por distintos pobladores en cercanías al humedal Laguna de Sonso.

Por otro lado, las condiciones ecológicas, hidrológicas y socioambientales para los humedales que integran la Reserva se clasifican, según la Corporación Autónoma Regional (2007), en conflictos ambientales de transformación y perturbación como resultado de intervenciones y acciones que se han materializado en el tiempo por parte de instituciones públicas, propietarios de predios privados y agentes sociales, pertenecientes a las comunidades que hacen uso de este ecosistema. En este contexto, los conflictos con mayor importancia corresponden a: el taponamiento del Caño Carlina en el año de 1966; la construcción de diques y canales por parte de propietarios privados; la introducción de flora y fauna invasora por distintos agentes sociales; contaminación por actividades agropecuarias y vertimiento de aguas residuales en los humedales; localización de población cerca al humedal sin contar con medidas de saneamiento básico, inadecuado manejo de aguas residuales, así como disposición de escombros y residuos sólidos en la Reserva; explotación de recursos biológicos y pesca desmedida por parte de distintos agentes sociales.

\section{Metodología}

Para llevar a cabo el análisis multitemporal de los humedales se incorporó técnicas de investigación cualitativas y cuantiabas que permitieran interpretar cada uno de los cambios presentes en las coberturas. Para lo anterior, se realizaron dos etapas en el proceso, las cuales se describen a continuación:

Primero: atreves de los Sistemas de Información Geográficos (SIG) y el empleo de software para la interpretación y geoprocesamiento de información remota (imágenes aéreas y satelitales) se calculó cambios y retrocesos en coberturas asociadas a los humedales para distintas fechas, correspondientes a 1944, 1986, 1998 y 2014, así 
mismo, se determinó los cambios presentes en la Figura 1 asociados a la expansión en áreas destinadas a la siembra de caña de azúcar en el valle geográfico del río Cauca entre 1986 - 2014. Las coberturas del suelo evaluadas corresponden a Cuerpos de agua, Cultivos caña de azúcar, Cultivos transitorios, Suelo desnudo y pastos y vegetación boscosa. En ese sentido, se produjeron y procesaron fotomosaicos a partir de aerofotografías suministradas por la Corporación Autónoma Regional del Valle del Cauca -CVC- a escala 1:30000 y 1:32000. Las imágenes satelitales empleadas corresponden a Landsat 5 TM y Landsat 8, descargadas de los servidores Global Land Facility y del Earth Explorer (USGS Science for a Changin Wold) Path 9 Row 57 / 58. Los software para el geoprocesamiento y elaboración cartográfica fueron Arc Gis 9.3 y Envi 4.7 respectivamente. En la Tabla 1 se ilustran las aerofotografías empeladas en el trabajo.

Tabla 1. Aerofotografías empleadas para la construcción de mosaicos

\begin{tabular}{|c|c|c|c|c|c|c|c|c|c|c|c|c|}
\hline \multirow{3}{*}{$\begin{array}{l}\text { Sombre } \\
\text { humedal }\end{array}$} & \multirow[t]{3}{*}{ Municipio } & \multirow{3}{*}{$\begin{array}{c}\text { Zona } \\
\text { de } \\
\text { estudio }\end{array}$} & \multicolumn{10}{|c|}{ Fotografías } \\
\hline & & & \multicolumn{5}{|c|}{ IGAC* } & \multicolumn{5}{|c|}{ FAL ** } \\
\hline & & & Vuelo & Sobre & $\begin{array}{c}\text { No. } \\
\text { Fotos }\end{array}$ & ESCALA & AÑ̃O & VUELO & FAJA & $\begin{array}{c}\text { No. } \\
\text { FOTOS }\end{array}$ & ESCALA & Ẫ̃o \\
\hline \multirow{7}{*}{$\begin{array}{l}\text { aguna de } \\
\text { Sonso, } \\
\text { Idreviejas } \\
\text { l Burro y } \\
\text { I Marina }\end{array}$} & \multirow[t]{7}{*}{ Buga } & \multirow[t]{7}{*}{ Centro } & \multirow[t]{3}{*}{ C-365 } & \multirow[t]{3}{*}{ S-915 } & 711 & \multirow[t]{3}{*}{$1: 33.000$} & \multirow[t]{3}{*}{1.944} & \multirow[t]{7}{*}{ Fal 407} & \multirow[t]{3}{*}{ F-37 } & 182 & \multirow[t]{3}{*}{$1: 31000$} & \multirow[t]{7}{*}{1.998} \\
\hline & & & & & 713 & & & & & 183 & & \\
\hline & & & & & 714 & & & & & 184 & & \\
\hline & & & \multirow{4}{*}{\begin{tabular}{|l|} 
C- \\
2249 \\
\end{tabular}} & \multirow[t]{4}{*}{ S-648 } & 240 & \multirow[t]{4}{*}{\begin{tabular}{|l|}
$1: 29.900$ \\
\end{tabular}} & \multirow[t]{4}{*}{1.986} & & \multirow[t]{4}{*}{ F-40 } & 476 & \multirow[t]{4}{*}{$1: 30850$} & \\
\hline & & & & & 241 & & & & & 477 & & \\
\hline & & & & & 242 & & & & & 478 & & \\
\hline & & & & & 243 & & & & & 479 & & \\
\hline
\end{tabular}

Fuente: Elaboración propia a partir de información suministrada por la Corporación Autónoma Regional del Valle del Cauca -CVC-

Este proceso permitió obtener Mapas Cronológicos que posibilitaron la evaluación de cambios en cada una de las coberturas incluyendo el avance y retroceso del espejo de agua en los humedales, además, facilitó el calculó de una tasa de cambio porcentual para los respectivos humedales en el tiempo. La cartografía elaborada se corroboró con previo trabajo en campo y la participación activa agentes sociales comunitarios claves en el área de estudio. Dichos agentes se escogieron mediante muestreo teórico, es decir que el investigador los selecciona mediante el "conocimiento teórico que se va construyendo sobre la marcha, con la información que va emergiendo a lo largo del estudio" o del proceso de investigación (Martínez, 2012: 616). El muestreo teórico se considera no probabilístico debido a que "se sustenta en el conocimiento previo del problema (Rincón y Barreto, 42: 2013) como una forma de acercarse a la representatividad de las muestras. 
Segundo: A partir de métodos cualitativos, se realizaron talleres de cartografía con agentes sociales, lo anterior para identificar usos, cambios y corroborar coberturas del suelo para cada una de las fechas observadas a través de la cartografía. En la realización de los talleres, los asistentes identificaban coberturas del suelo asociadas a cada una de las fechas evaluadas mediante líneas de tiempo. Estos agentes sociales presentaban edades entre los 30 y 80 años respectivamente, entre otras cosas, eran conocedoras de las actividades económicas productivas de la zona. Posteriormente, se colecto información a partir de entrevistas semi-estructuradas, las cuales toman la forma de "una conversación que gira alrededor de un cuestionario abierto con el fin de poder desentrañar información de "ciertos aspectos de la vida de las personas (Létourneau, 2009: 16), que se hace necesario comprender e interpretar para acercarse a la reflexión sobre las distintas lógicas de producción socioespacial. Con la entrevista fue posible definir categorías de análisis, que posteriormente, mediante el análisis de contenido, se convirtieron en insumo para interpretar los cambios presentes en la cartografía. El análisis de contenido es una "técnica de investigación para la descripción objetiva, sistemática [...] del contenido manifiesto de las comunicaciones con el fin de interpretarlas" (Berelson en Hernández, 1994: 301 citado por Cáceres, 2003: 55), a partir de "un conjunto de técnicas de análisis de las comunicaciones (entrevistas y documentos) utilizando procedimientos sistemáticos y objetivos de descripción del contenido de los mensajes" (Bardin, 1996: 29 en Cáceres, 2003: 57) y sustentado en el componente teórico de la investigación. El propósito del análisis de contenido se refleja en la interpretación y comprensión que le permite al observador descifrar elementos y acciones que incidieron en la transformación de los humedales en el tiempo, que resulta imposible dilucidar desde el campo cuantitativo de las ciencias.

Figuras $6 \mathrm{a}$ y $6 \mathrm{~b}$. Trabajo en campo con agentes sociales, Reserva Natural Laguna de Sonso

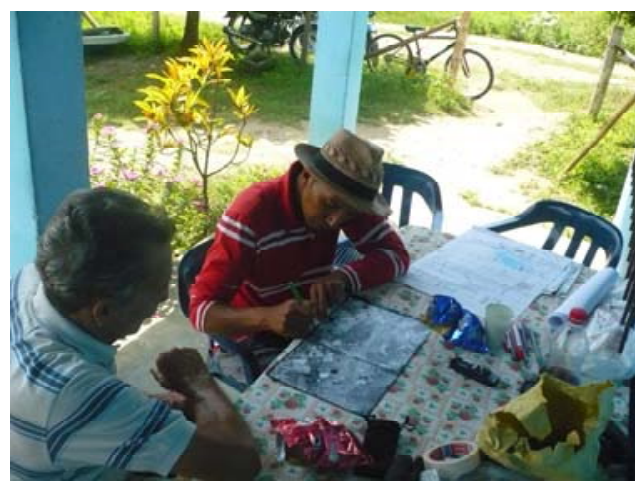

Figura 6a. Talleres de cartografía social y corroboración de coberturas.

Fuente: Elaboración propia

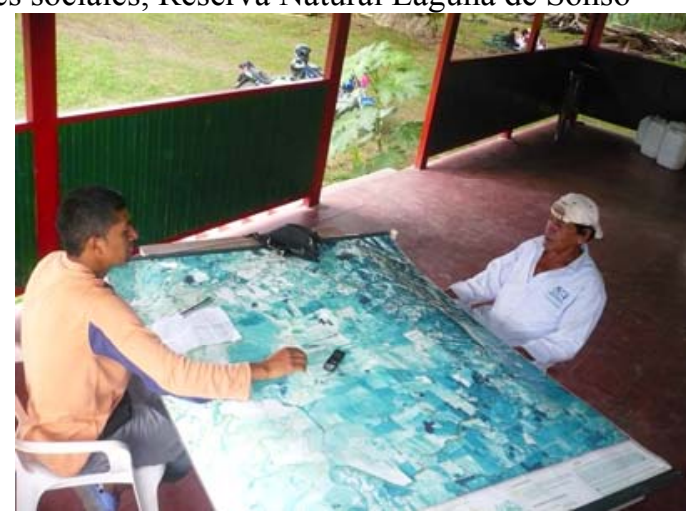

Figura $6 \mathrm{~b}$. Talleres de cartografía social y corroboración de coberturas. 
Una vez obtenida la información cualitativa y cuantitativa se interpretó a partir de la técnica de triangulación de la información, la cual consiste en estudiar al mismo tiempo distintas fuentes de datos para interpretar y analizar un mismo fenómeno, pero también es entendida como la "técnica de confrontación y herramienta de comparación de diferentes tipos de análisis de datos" (Aguilar y Barroso, 2015: 74). En este caso se triangularon documentos normativos, talleres de cartografía social, mapas cronológicos y entrevistas a los agentes sociales. En las Figuras $6 \mathrm{a}$ y $6 \mathrm{~b}$ se observa parte del trabajo de cartografía en campo con algunos de los agentes sociales seleccionados.

\section{Resultados}

A continuación se presenta el análisis multitemporal correspondiente a los humedales de la Reserva Natural Laguna de Sonso, integrando la información cuantitativa suministrada por el SIG y cualitativa recolectada a partir de talleres, entrevistas y fuentes secundarias. De esta forma, los cambios presentes en las distintas coberturas se contrastan con las voces y el saber de los agentes sociales que han intervenido en la transformación de los humedales.

En la Figura 7 se presenta la gráfica de porcentajes de cobertura del suelo para los humedales de estudio en el periodo de tiempo comprendido entre 1943 y 2014. Dicha gráfica se construyó en escala logarítmica de base diez, puesto que permite observar mejor los valores en hectáreas para cada una de las coberturas del suelo que se encuentran por debajo de 10 hectáreas. Por otro lado, la Tabla 2 contiene el área en hectáreas (ha) de las distintas coberturas y la tasa de cambio porcentual asociada a los años evaluados, y la Figura 8 espacializa la cartografía obtenida del SIG para las distintas fechas evaluadas.

El humedal La Marina en términos de tasa de cambio porcentual para los años 1944 y 1986 presentó un aumento de 9,62\% (ver Figura 8), siendo el humedal de mayor incremento para ese periodo, pasando de un área base de 14.66 ha., para el año de 1944 a 16,08 ha., en el año 1986. Igualmente, entre 1998 y 2014, la tasa de cambio porcentual evidenció un leve incremento de 4,91\%, de su cobertura en espejo de agua laminar (ver Tabla 2). La hipótesis más frecuente, según los agentes entrevistados, con respecto a dicho aumento del espejo de agua, se debió a la presencia de la Corporación Autónoma Regional del Valle del Cauca -CVC- en la Reserva, una vez se adquieren los predios de la Hacienda Bello Horizonte en el año 2001 (Corporación Autónoma Regional dl Valle del Cauca -CVC-, 2007: 6), donde actualmente se localiza el Centro Ambiental Buitre de Ciénaga y el humedal La Marina. Entre 1986 y 1998 se registra la tasa de cambio de mayor retroceso en el tiempo de este humedal, que corresponde a $-39,11 \%$, siendo la mayor perdida en relación al resto de humedales en la Reserva (ver Figura 7 y Tabla 2). 
Figura 7. Porcentaje de coberturas por año evaluado, Reserva Natural Laguna de Sonso, entre 1943 y 2014.

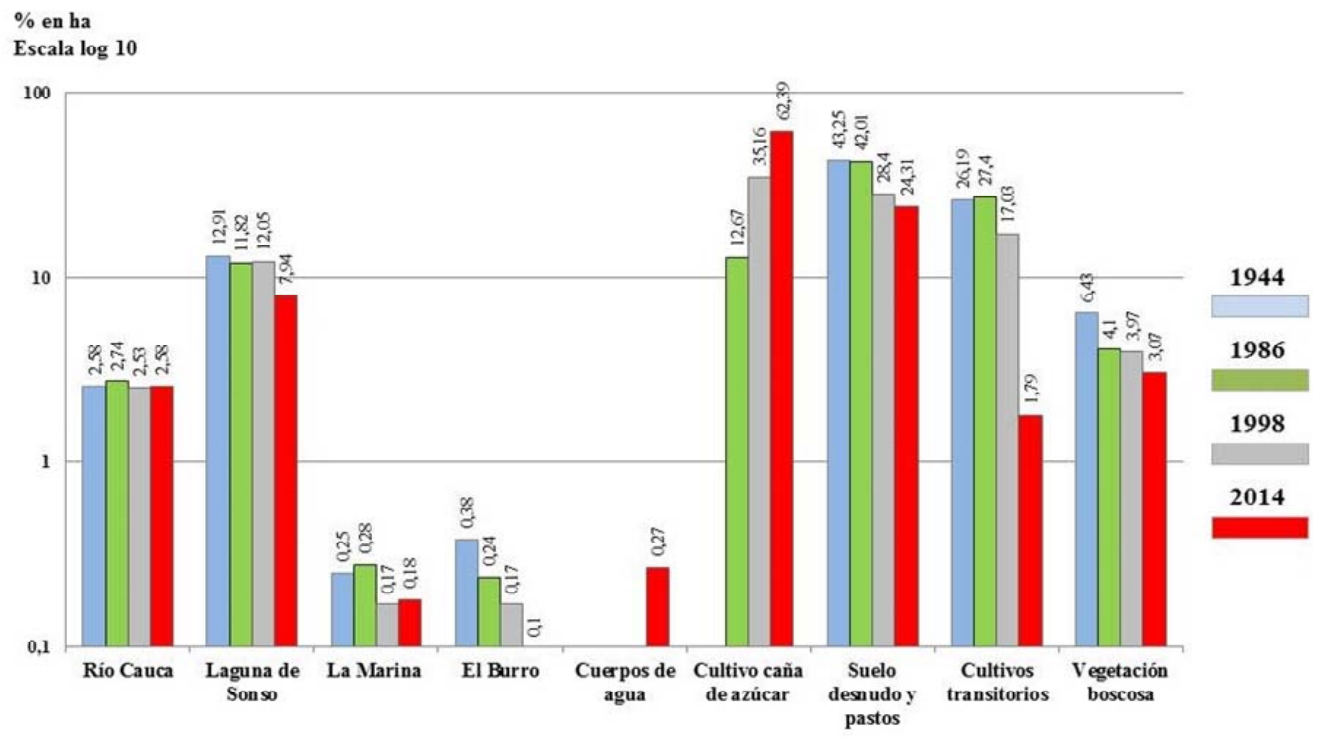

Fuente: Elaboración propia

El humedal El Burro presenta disminución de su área en todos los años evaluados (ver Figura 7), en el cual, las mayores pérdidas corresponden al año 2014, pasando de un $0,38 \%$ a representar un $0,10 \%$ del porcentaje total. En la Tabla 2 se observa la disminución en área del humedal en relación al año base de 1944 y 2014, cuyo descenso es de 21,76 ha., a 5,66 ha. La tasa de cambio porcentual más crítica para el humedal el Burro corresponde al periodo comprendido entre los años 1998 y 2014 con un $-42,39 \%$, cifra que refleja un retroceso de 9.83 ha., a 5,66 ha.

Al mirar en conjunto los años evaluados, se observa que la cobertura "Cultivo Caña de Azúcar" presenta la mayor expansión espacial, pasando de 733,80 ha., para el año 1986, 3.614,76 ha., en área sembrada para el año 2014; Elemento que se soporta con tasas de cambio porcentual de $177,61 \%$ para el primer caso (1986 y 1998) y $77,45 \%$ para el segundo caso (1999 y 2014). Este hecho espacial se evidencia en la Figura 8, donde se observa el patrón espacial de desplazamiento de otras coberturas por la presencia del cultivo de la caña de azúcar (ver Figura 8). 
Tabla 2. Tasa de cambio porcentual para las coberturas asociadas a los humedales de la Reserva Natural Laguna de Sonso.

\begin{tabular}{|c|c|c|c|c|c|c|c|}
\hline \multirow[t]{2}{*}{$\begin{array}{l}\text { Coberturas del } \\
\text { suelo }\end{array}$} & \multicolumn{4}{|c|}{ Total hectáreas / año } & \multirow[t]{2}{*}{$\begin{array}{c}\text { \% de cambio } \\
1944-1986\end{array}$} & \multirow[t]{2}{*}{$\begin{array}{c}\text { \% de cambio } \\
1986-1998\end{array}$} & \multirow[t]{2}{*}{$\begin{array}{c}\% \text { de } \\
\text { cambio } \\
1998 \text { - } \\
2014 \\
\end{array}$} \\
\hline & 1944 & 1986 & 1998 & 2014 & & & \\
\hline Río Cauca & 149,53 & 158,52 & 146,52 & 149,40 & 6,02 & $-7,57$ & 1,96 \\
\hline $\begin{array}{l}\text { Laguna de } \\
\text { Sonso } \\
\end{array}$ & 1153,66 & 684,56 & 698,34 & 460,15 & $-40,66$ & 2,01 & $-34,11$ \\
\hline $\begin{array}{c}\text { Humedal La } \\
\text { Marina }\end{array}$ & 14,66 & 16,08 & 9,79 & 10,27 & 9,62 & $-39,11$ & 4,91 \\
\hline El Burro & 21,76 & 13,67 & 9,83 & 5,66 & $-37,15$ & $-28,10$ & $-42,39$ \\
\hline $\begin{array}{c}\text { Otros Humeda- } \\
\text { les }\end{array}$ & 8,34 & 0,00 & 0,00 & 0,00 & $-100,00$ & $*$ & $*$ \\
\hline $\begin{array}{c}\text { Cuerpos de } \\
\text { agua (lagos) }\end{array}$ & 0,00 & 0,00 & 0,00 & 15,57 & $*$ & $*$ & 0,00 \\
\hline $\begin{array}{l}\text { Cultivo Caña } \\
\text { de Azúcar }\end{array}$ & 0,00 & 733,80 & $2.037,10$ & $3.614,76$ & 0,00 & 177,61 & 77,45 \\
\hline $\begin{array}{c}\text { Cultivos } \\
\text { Transitorios } \\
\end{array}$ & $1.517,42$ & $1.587,42$ & 986,79 & 103,65 & 4,61 & $-37,84$ & $-89,50$ \\
\hline $\begin{array}{c}\text { Suelo Desnudo } \\
\text { y Pastos }\end{array}$ & $2.505,43$ & $2.317,73$ & $1.645,60$ & $1.408,51$ & $-7,49$ & $-29,00$ & $-14,41$ \\
\hline $\begin{array}{c}\text { Vegetación } \\
\text { Boscosa }\end{array}$ & 375,73 & 237,79 & 229,96 & 177,99 & $-36,71$ & $-3,29$ & $-22,60$ \\
\hline
\end{tabular}

La tasa de Cambio porcentual se calculó a partir de la siguiente ecuación:

$\Delta \mathrm{x}=\left(\mathrm{X}_{2}-\mathrm{X}_{1}\right) / \mathrm{X}_{1} * 100$. Donde $\mathrm{X}_{1}$ corresponde al primer año observado $\mathrm{y} \mathrm{X}_{2}$, al segundo año por arriba de $\mathrm{X}_{1}$.

$\Delta \mathrm{x}$ corresponde al cambio porcentual.

Los valores negativos (-) indican pérdida y retroceso de cobertura.

Los valores positivos indican un aumento o ganancia de cobertura.

Los valores en cero $(0)$ indican que la cobertura aparece por primera vez.

Los cuadros con el símbolo (*) indican que la cobertura no existe aún

Fuente: Elaboración propia.

Para el año de 1944 no había presencia de cultivos de caña de azúcar en el área de estudio; según la Tabla 2, para la década de 1986 el número total en hectáreas de esta cobertura, correspondía a 733,80 ha.; en tanto que, para el año 1998, su área estaba en 2.037,10 ha., llegando casi a triplicarse. La tasa de cambio porcentual presenta un incremento de 177, 61\%, valor que representa el mayor incremento en relación al resto de las coberturas evaluadas en la Reserva Natural (ver Tabla 2). Para el periodo comprendido entre los años de 1998 y 2014, la tasa de cambio porcentual continua evidenciando crecimiento en esta cobertura, con un $77,45 \%$; pasando de 2.037,10 ha., para el año base de 1998 a 3.614,76 ha., para el año 2014.

La cobertura "Cultivos Transitorios" presenta descenso en el porcentaje de su área total para los años 1998 y 2014 (ver Figura 8); para el año de 1986 se registra un aumento de $27.40 \%$ según la Tabla 2 (ver Tabla 2). Las mayores pérdidas en área para esta cobertura corresponden a los años comprendidos entre 1998 y 2014, con una 
tasa de $-89.50 \%$, pasando de 986,79 ha., en el año base de 1998, a 103,66 ha., para el año 2014. Los cambios espaciales se observan en la Figura 9 (ver Figura 8).

Figura 8. Mapas cronológicos humedales Reserva Natural Laguna de Sonso, 1944 - 2014.
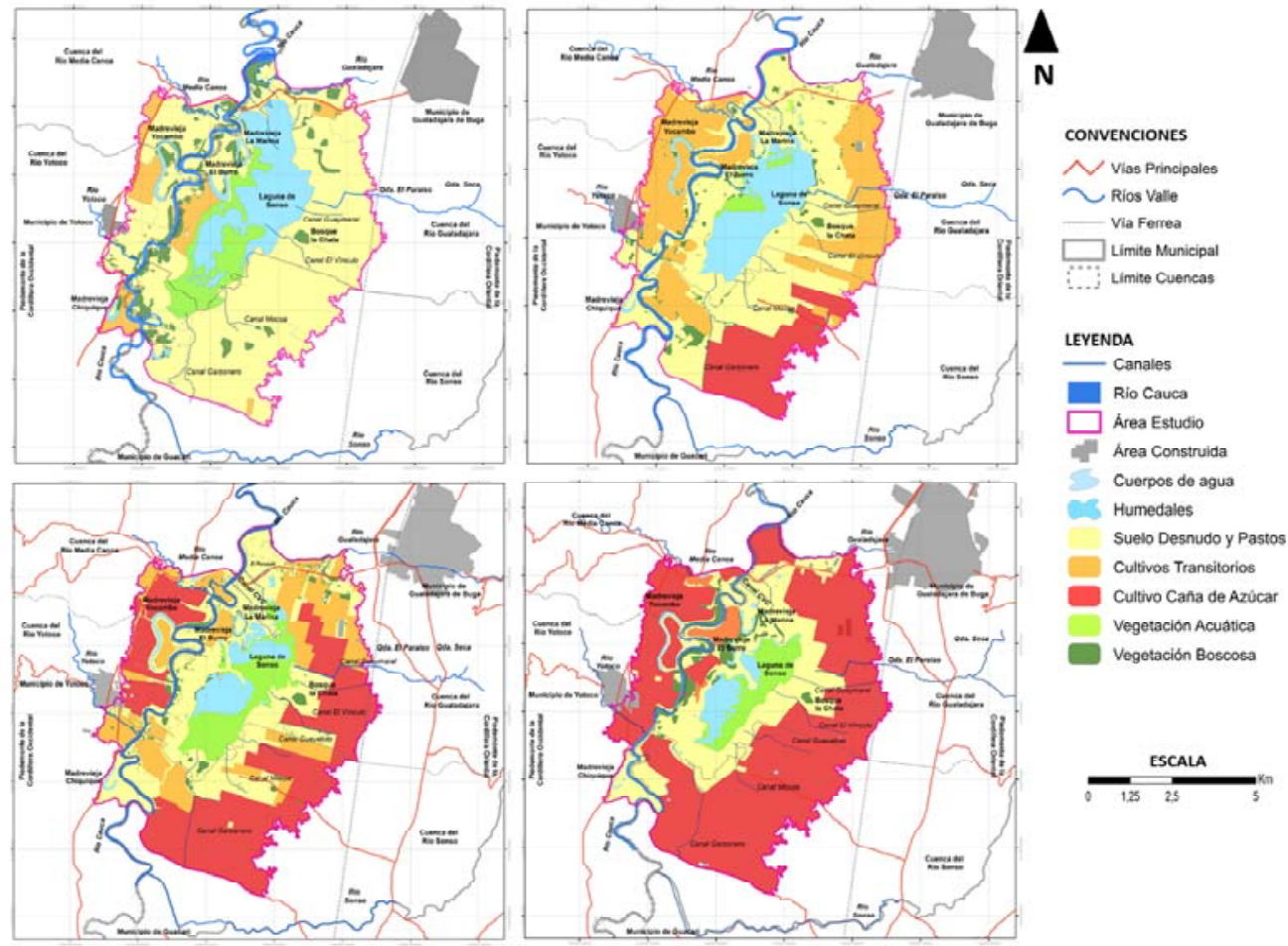

Fuente: Elaboración propia

La cobertura "Suelo Desnudo y Pastos" presenta descensos en los distintos años evaluados (ver Figura 8), pasando de $43,25 \%$ en el año de 1944 a $24,31 \%$ en el año 2014. Por otro lado, la tasa de cambio porcentual con la mayor pérdida se refleja en el periodo comprendido entre 1986 y 1998 con un $-29 \%$, pasando de $2.317,73$ ha., para el año base de 1986 a 1.643,60 ha., para el año 1998 (ver Tabla 2). Este comportamiento espacial se evidencia en la Figura 8, en la cual es posible identificar la manera en que la cobertura dominante asociada a "Suelo Desnudo y Pastos" retrocede en el tiempo dando paso a la materialización de otras prácticas productivas de mayor tecnificación, como la caña de azúcar.

La cobertura "Vegetación Boscosa" presenta descensos en cada uno de los años evaluados, según la Figura 8. Su tasa de cambio porcentual con las mayores pérdidas hace referencia al periodo comprendido entre 1944 y 1986, con un descenso de $36,71 \%$; esta pérdida se traduce a 375,73 ha., para el año base de 1944 y 237,79 ha., 
para el año 1986 (ver Tabla 2). Actualmente existen relictos de bosque en la Reserva, buena parte de ellos intervenidos por la Corporación Autónoma regional -CVC-, sin embargo, estos bosques se localizan en predios privados, situación que dificulta las labores pertinentes de la autoridad ambiental.

\section{Contrastes entre los cambios presentes en la cartografía y las voces de algunos agentes sociales comunitarios}

Los contrates entre los cambios presentes en la cartografía y las voces de algunos agentes sociales entrevistados, permiten comprender y entender la forma en la cual se han ido transformado los humedales en el tiempo. Esto es posible al integrar la información cualitativa y cuantitativa a partir de técnicas de triangulación de la información.

Según los agentes sociales entrevistados, hacia mediados del siglo $\mathrm{XX}$, los humedales de la Reserva se caracterizaban por un tipo de paisaje con alta presencia de bosques, pastos para ganadería y cultivos de subsistencia (maíz, millo, plátano), así, como por la presencia de grandes haciendas dedicadas al desarrollo económico de actividades agropecuarias, en especial, ganadería. En inmediaciones a los humedales, se resalta la presencia de pastos, bosques y cultivos, además, de los distintos canales naturales de conexión entre humedales, el río Cauca y otros afluentes. En palabras de uno de los agentes entrevistados se evidencia lo siguiente:

Cuando yo llegué por aquí, habían bosquecitos [...] en la hacienda Rancho Grande también habían bosquecitos, puros Mantecos y eso lo acabaron, [...] para allá eran cultivos de caña; llegué a conocer cultivos de soya, maíz alrededor del humedal. Y alrededor de los humedales eran pastos y ganadería

(Entrevista agente social, Corregimiento El Porvenir, 2014)

El agente social resalta la presencia de bosques al interior de las haciendas, elemento que, según los actores entrevistados, se evidencia en la distribución espacial de la cobertura asociada a "Vegetación Boscosa" en la Figura 9 respectivamente (ver Figura 8) en los cuales se observa como la cobertura "Vegetación Boscosa" escenifica un patrón irregular; y donde la mayor parte de ésta cobertura se localiza a los costados del río Cauca, que según los agentes entrevistados, concuerda con antiguas haciendas que en sus procesos productivos incorporaban prácticas agropecuarias asociadas a relictos de bosque.

También, se destaca que los distintos pobladores entrevistados manifestaban una serie de diferencias en términos de su percepción frente a la gestión de los humedales por parte de las instituciones que representan al Estado. Según los agentes entrevistados, las distintas decisiones tomadas en el tiempo a través de los órganos públicos, no han logrado generar el impacto adecuado con respecto al estado del 
ecosistema Laguna de Sonso, por el contrario, sienten que las distintas medidas optadas por la CVC únicamente han beneficiado a los intereses de actores que representan el sector privado, puesto que, en la medida que se pierde espejo de agua lagunar, se avanza por parte de los propietarios privados en la adquisición de predios que pertenecen al humedal.

Figuras 9a y 9b. Intervenciones antrópicas al interior de la Reserva Natural Laguna de Sonso

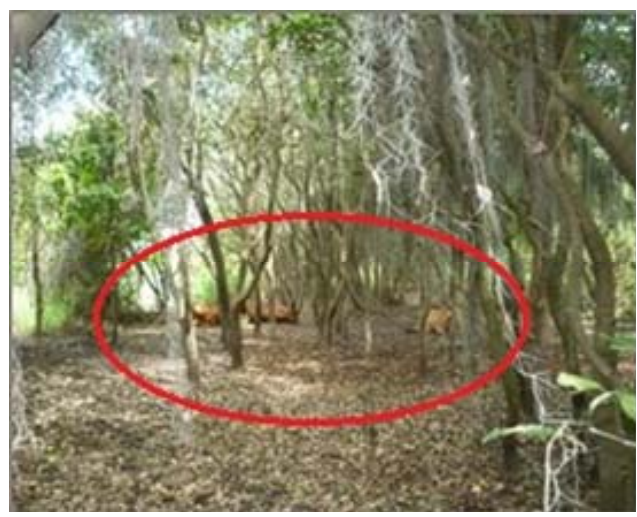

Figura 9a. En el círculo se observa la presencia de ganado al interior del humedal Laguna de Sonso.

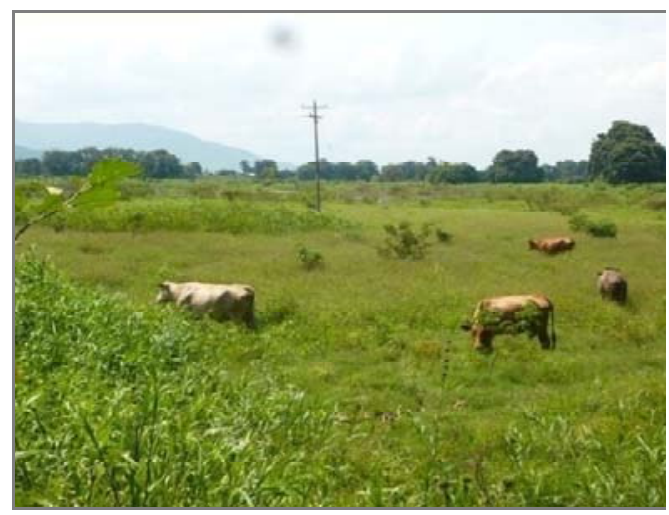

Figura 9b. Intervención de agentes privados con ganado en el área de protección de la Reserva Natural Laguna de Sonso.

Fuente: Aguirre y Perdomo (2015: 174)

Otro elemento que destaca, es el área de influencia del humedal, que se ha concebido de distintas formas, cada una de ellas dependiendo del agente social; para la élite y los capitalistas de dos formas: la primera, el humedal como freno al desarrollo regional y otra el Valle del Cauca como un emporio de agronegocio; para los campesinos vinculados a actividades de subsistencia el humedal se concibe como el medio natural que provee y suple parte de sus necesidades básicas, entre ellas, la pesca artesanal, caza de animales silvestres y prácticas de esparcimiento.

Con respecto a lo anterior, los agricultores capitalistas en la década de los años 50 del siglo XX concebían la Reserva como una amenaza a sus actividades productivas, lo cual en su momento iba en contravía de las políticas del Estado. Los agentes sociales entrevistados concuerdan en aspectos relacionados con el papel de las distintas políticas que han incidido en las condiciones socioambientales de los humedales y el rol de las instituciones que representan al Estado a la hora de proteger, gestionar y ejecutar acciones encaminadas a la defensa y conservación de estos ecosistemas. En relación a lo anterior, los actores entrevistados se refieren a éstos elementos como detonantes que han influido de manera directa en los mayores cambios del paisaje de estos ecosistemas. 
En ese sentido, uno de los primeros detonantes registrados según el Plan Ambiental Integral Humedal Reserva Natural Laguna de Sonso (Corporación Autónoma Regional del Valle del Cauca -CVC-, 2007) se remonta al año 1955, el cual se describe por parte de Aníbal Patiño (Patiño, 1970 en Corporación Autónoma Regional del Valle del Cauca -CVC-, 2005 :3) las primeras intervenciones a los humedales en favor de la producción agrícola realizadas por los propietarios de predios privados vecinos, a partir de la construcción de diques, a fin de impedir las inundaciones del rio Cauca y el río Sonso sobre predios cultivados; acciones que cambiaron la hidrodinámica de los humedales, en especial el humedal Laguna de Sonso; tales intervenciones lograron la obstrucción de la conexión río - humedal en sentido sur - norte. En consecuencia, las acciones impidieron que durante los periodos de desbordamiento del río Cauca, la vegetación flotante y el sedimento, fuesen arrastrados del interior del humedal hacia el río.

Según los agentes entrevistados, el hecho social que contrarrestó la amenaza que representaba el humedal para muchos de los agentes capitalistas, está asociado a la construcción de la carretera Buga-Mediacanoa-Buenaventura para el año 1966. Intervención que resuelve momentáneamente la amenaza para dichos agentes capitalistas. Para el mismo periodo los gobiernos de turno, bajo la idea de modernización del Estado, intentan conectar vía terrestre el centro del país con el Pacífico colombiano. Como consecuencia de la construcción, se obstaculizaron distintos canales de salida de agua del humedal Laguna de Sonso, en especial, el taponamiento del Caño Carlina, que para la época se consideraba el canal más importante en la función natural de desagüe del humedal; la interrupción del canal incidió en la composición bioquímica del agua, pues la vegetación flotante (como el Buchón de agua) al no ser evacuada, comenzó a interferir en la disponibilidad de oxígeno disuelto en agua y la incorporación de luz solar para el ecosistema. La concepción del humedal como elemento en contravía del desarrollo regional, se logra apreciar en palabras de uno de los agentes entrevistados con el siguiente argumento:

\section{Esta vía fue construida en 1966 [...] la carretera anterior tenía siete puentones y tenía el Caño Carlina que era un caño que no quedaba en lo alto sino en lo bajo; entonces, el buchón y el sedimento caía hacia abajo, no cogía hacia arriba [...] entonces, cuando cambiaron el Caño Carlina [...] le quitaron los puentones a la laguna, le quitaron las salidas al agua y lo llenaron de árboles; el árbol tapona la salida del buchón. Ahí quedó estancada la laguna, con eso tuvo para morirse la Laguna de Sonso}

(Entrevista agente social, Corregimiento El Porvenir, 2014)

En vista de lo sucedido, se concibe la construcción de un nuevo canal para el año de 1969 por parte de la CVC, institución que representa al Estado, como respuesta a la situación ambiental que se generó por la intervención de la carretera para la época. Según el Plan Ambiental Integral Humedal Reserva Natural Laguna de Sonso (CVC, 2007) este nuevo canal aceleró los procesos de sedimentación, obstaculizando la salida de vegetación flotante al interior del humedal, igualmente impidió la 
renovación de aguas y la entrada de peces que requieren de las condiciones biológicas del humedal para su desarrollo.

En el ámbito regional e internacional, la Reserva fue declarada como zona de Reserva Natural Laguna de Sonso, mediante el Acuerdo CVC No. 17 de 1978 (Corporación Autónoma Regional del Valle del Cauca-CVC-, 2005, 4), con el fin de planificar el humedal en términos de la conservación de especies migratorias y locales; en función a los atributos del paisaje; en pro de mantener equilibrio en el ecosistema; recreación; y en miras a la promoción de conocimiento científico. Postura que asumen los institutos Von Humboldt y el Bird Life Internacional, al declarar la Reserva como área importante en la conservación de aves $(2007,4)$. Posteriormente, para finales del siglo XX, el INCORA (Instituto Colombiano de la Reforma Agraria) y el IGAC (Instituto Geográfico Agustín Codazzi) inician el deslinde o delimitación del Humedal Laguna de Sonso, que según el Plan Ambiental Integral (Corporación Autónoma Regional del Valle del Cauca-CVC-, 2007) pretendía establecer mojones en 18 de los 23 predios que colindaban con la Laguna. Uno de los agentes entrevistados hace referencia al proceso de deslinde del humedal para la época, de la siguiente manera:

Yo trabaje para el 94, 95 en el levantamiento topográfico de todo esto, y entonces, esta es la fecha que no han entregado los documentos, ni la CVC, ni el INCORA [...] ellos tenían la obligación del deslinde de todos los humedales para la fecha de la Reserva

(Entrevista agente social, Corregimiento El Porvenir, 2014)

Entre las distintas actividades económicas de subsistencia desarrolladas por los agentes sociales en la Reserva, se destaca la pesca artesanal como una de las más importantes. Esta actividad ha estado ligada históricamente a pobladores cercanos de los humedales, práctica que representaba uno de los principales medios de subsistencia para buena parte de las primeras familias localizadas cerca a estos ecosistemas. Actualmente, la actividad de la pesca refleja condiciones lamentables en términos socio-ambientales, producto de una serie de intervenciones que han incidido directamente en el número de peces y la calidad del agua de los humedales, entre las que sobresalen: contaminación por residuos químicos provenientes de la zona industrial de Yumbo y el sector agroindustrial; metales pesados derivados de actividad minera en el Alto Cauca; y los bajos niveles de oxígeno disuelto en el agua del río.

Actualmente, los humedales vienen reduciendo su área en espejo lagunar y franjas de protección, producto de la ocupación y apropiación de agentes privados a través de determinadas prácticas productivas. Una de las modalidades identificadas de apropiación del área en los humedales por parte de agentes privados se presenta cuando estos ecosistemas empiezan a disminuir sus niveles de agua; entonces, las áreas descubiertas en espejo lagunar son ocupadas con presencia de ganadería; posteriormente, dichas áreas son delimitadas e incorporadas a los terrenos de estos 
agentes. En palabras de uno de los actores entrevistados se puede evidenciar la manera en la cual, agentes capitalistas se apropian de las áreas de los humedales, argumento que se sustenta en las Figuras $9 \mathrm{a}$ y $9 \mathrm{~b}$ respectivamente:

\section{[...] pero que sucede, cuando la laguna ha bajado el dueño de la finca comienza: vea, al agregado, hermano diez métricos hacia allá, auménteme allí en pasto que ahí son cincuenta novillos que levanto}

(Entrevista agente social, Corregimiento El Porvenir, 2014)

\section{Conclusiones}

Es evidente que se presentaron cambios en el paisaje de los humedales entre mediados del siglo XX y principios del siglo XXI asociados a pérdidas en área de coberturas importantes como bosques, espejo de agua laminar y cultivos transitorios, las cuales han cedido sus áreas a la expansión del monocultivo de la caña de azúcar. Así mismo, los agentes sociales entrevistados identificaron que los actores capitalistas han propiciado las mayores transformaciones en los ecosistemas en el tiempo, mediante sus formas de concebir el espacio y desarrollo económico. La concepción de desarrollo incorporada en el Departamento a mediados del siglo XX por las élites de la región, quienes veían en el valle geográfico del río Cauca oportunidades para el crecimiento económico capitalista, definió el rumbo y la forma de planificación del Valle del Cauca y sus humedales.

En dicha visión de desarrollo, era necesario regular las frecuentes inundaciones del río Cauca, dando paso a procesos de adecuación de tierras para la implementación de prácticas agropecuarias a gran escala. En esta fase de producción social del espacio, los humedales y otros ecosistemas representativos del valle geográfico del río Cauca, se veían como obstáculos a la consecución de tales objetivos.

Entre las acciones más significativas que han propiciado el deterioro de humedales en Valle del Cauca, se resalta el papel que han jugado las élites regionales, quienes concibieron la planicie aluvial del río Cauca como un área de expansión del monocultivo de la caña de azúcar, práctica material que sustenta el modelo de desarrollo del agronegocio para la región, desde mediados del siglo XX y consolidado en nuestros días. Este hecho se ve reflejado en la constante disminución del espejo de agua del humedal Laguna de Sonso, el cual pasó de 1153,56 ha. Para el año base de 1944, a tan solo 693,51 ha., para el año 2014; con una tasa promedio de retroceso anual de 9,90 hectáreas. Cifra significativa, que sí logra mantenerse constante, al cabo de 70 años aproximadamente, habrá desaparecido por completo el espejo de agua laminar del humedal Laguna de Sonso.

Las transformaciones del paisaje y el estado lamentable de la Reserva Natural Laguna de Sonso, se han materializado producto de intervenciones por parte de agentes estatales y agentes privados, a partir de acciones y decisiones que hasta el momento no han arrojado los mejores resultados en materia de conservación, deslinde y mejoramiento de la calidad socioambiental para estos ecosistemas, por el contrario, 
dichas acciones han favorecido la materialización de las concepciones espaciales de agentes privados mediante la expansión del monocultivo de la caña de azúcar. Como resultado de estas acciones se destaca: la sedimentación acelerada de humedales; reducción del área en espejo lagunar y bosque protector; disminución y desaparición de especies locales, y detrimento en calidad de vida de las comunidades que hacen uso de los ecosistemas para subsistencia.

Sin embargo, pese a los esfuerzos de concebir la Reserva Natural como patrimonio para el departamento del Valle del Cauca y la región por su importancia ecológica, la diversidad de especies que esta alberga, y su valor paisajístico, desde el año de 1978, actualmente, dicha designación no se ha materializado por parte de las entidades que representan al Estado como la Corporación Autónoma Regional del Valle del Cauca CVC-y el Instituto Colombiano de Desarrollo Rural -INCODER-, ya que, a la fecha, no se ha podido avanzar en la diferenciación de predios privados y áreas que pertenecen a la Reserva; si bien, hubo un intento de deslinde para el año de 1996, hoy en día no se conocen los resultados de dicho proceso. Esta situación se ha convertido en obstáculo para la toma de decisiones, por parte de agentes sociales comunitarios, en materia de delimitación del área de conservación de humedales, así, como en la diferenciación de áreas dedicadas al desarrollo de actividades agroindustriales y agropecuarias, las cuales han incidido directamente en el deterioro progresivo de este ecosistema.

De los tres humedales observados, El Burro y la Marina evidencian avanzados procesos de sucesión natural; para el caso del primer humedal, este presenta el mayor grado de sedimentación, y en épocas de sequía registra los niveles de agua más críticos. El humedal Laguna de Sonso, sigue reduciendo su área en espejo lagunar y zonas amortiguadoras, producto del accionar antrópico, y mediante la ocupación y apropiación ilegal de áreas de la Reserva en épocas de sequía. A esto se suma la débil percepción que tienen los agentes sociales comunitarios entrevistados frente a las instituciones que representan el Estado, pues se traduce en escepticismo con respecto a los alcances que han logrado dichos agentes a lo largo de la historia en el marco de la gestión y conservación de estos ecosistemas.

Metodológicamente, se logró avances satisfactorios con respecto a la implementación de técnicas de investigación cualitativas y cuantitativas, propuesta que pocas veces se lleva a cabo desde el ámbito geográfico como alternativa investigativa y que permitió avanzar en el análisis de los cambios observados en coberturas a través de la cartografía, de manera que, fue posible identificar desde las voces de agentes sociales los elementos más significativos en la transformación del paisaje de los humedales en el tiempo; puesto que, quién mejor, que las comunidades que cotidianamente han producido estos espacios, para que sean ellos quienes cuenten a través del saber consuetudinario, las formas en que dichos ecosistemas han ido transformándose. 


\section{Referencias bibliográficas}

Aguilar, S y Barroso, J. (2015). La triangulación de datos como estrategia en investigación educativa. En: Píxel-Bit. Revista de Medios y Educación. Universidad de Sevilla, España. N. ${ }^{\circ}$ 47. pp 73-88

Aguirre, M.A y Perdomo Urrea, J.P. (2015) Producción socioespacial de siete humedales del Valle del Cauca, de mediados del siglo XX a principios del siglo XXI. Santiago de Cali, Colombia: Universidad del Valle, Facultad de Humanidades, Departamento de Geografía. pp, 63, 64, 65, 174

Álvarez López, H (1999): Guía de las aves de la Reserva Natural Laguna de Sonso. Cali, Colombia: Editorial CVC. p, 15

Castañeda Zuluaga, L. (2012): Análisis de las dinámicas espacio-temporales de la cobertura de la tierra en cuatro humedales en el departamento del Valle del Cauca. Universidad del Valle, Facultad de Humanidades, Departamento de Geografía. 2012. pp. 20,

Departamento Nacional de Planeación. (2011): Plan Nacional del Desarrollo 2010-2014: Más empleo, menos pobreza y más seguridad. Bogotá, D.C., Colombia. p, 611

Cáceres, P. (2003): Análisis cualitativo de contenido: una alternativa metodológica alcanzable. Pontificia Universidad Católica de Valparaíso, Chile. Revista Psicoperspectiva, Vol II. p, 55,57

Corporación Autónoma Regional del Valle del Cauca (2009): Humedales del valle geográfico del río Cauca: Génisis, biodiversidad y conservación. Santiago de Cali, Colombia. pp, 22, 175

Corporación Autónoma Regional del Valle del Cauca (2007): El río Cauca en su valle alto. Un aporte al conocimiento de uno de los ríos más importantes de Colombia. Universidad del Valle, Santiago de Cali, Colombia. pp, 1, 7

Corporación Autónoma Regional del Valle del Cauca (2005): Plan Ambiental Integral Humedal Laguna de Sonso, municipio de Guadalajara de Buga. Santiago de Cali. p 3, 4, 6

Fuenzalida, M; Buzai, G; Moreno, A y García De León, A. (2015): Geografía, Geotecnología y análisis Espacial: Tendencias, métodos y aplicaciones. Universidad Alberto Hurtado, Departamento de Geografía, Editorial el Triángulo. Santiago de Chile.

Gonzáles, A; Traba, J; Seoane, J y Morales, P. (2014): Aplicaciones de SIG y Teledetección en Ecología. Guion de prácticas de la asignatura. Universidad Autónoma de Madrid.

Ley 939. (2004): Por medio de la cual se subsanan los vicios de procedimiento en que incurrió en el trámite de la Ley 818 de 2003 y se estimula la producción y comercialización de biocombustibles de origen vegetal o animal para uso en Motores diesel y se dictan otras disposiciones.

Ley 1151. (2007): PLAN NACIONAL DE DESARROLLO 2006-2010. Estado comunitario: Desarrollo para Todos. Departamento Nacional de Planeación. Bogotá, D.C., Colombia. p, 222

Létourneau, J. (2009): La caja de herramientas del joven investigador: Guía de iniciación al trabajo intelectual. La Carreta Editores, E.U. Colombia, Santafé de Bogotá. p, 167.

Martínez Salgado, C. (2012). El muestreo en investigación cualitativa. Principios básicos y algunas controversias. Departamento de Atención a la Salud, Universidad Autónoma 
Metropolitana (Xochimilco). En: Ciênc. saúde coletiva vol.17 no.3 Rio de Janeiro. pp 613 $-619$

Patiño, A. (1998): Reserva Natural Laguna de Sonso Buga (1978-1988): De laguna a pantano en 10 años. Balance crítico y juicio de responsabilidades. Ponencia presentada en el $5^{\circ}$ Congreso de la Sociedad Colombiana de Ecología, Bogotá, Colombia.

Perafán, A. (2005): Transformaciones paisajísticas en la zona plana Vallecaucana. En Revista Historia y Espacio, Fascículo 24. Universidad del Valle. Cali, Colombia. pp. 1-18

Política Nacional para Humedales Interiores de Colombia. (2002): Ministerio del Medio Ambiente. Bogotá, D.C.

Rincón, J y Barreto, I. (2013). Técnicas de muestreo para investigaciones sociales. En: La investigación en ciencias sociales: estrategias de investigación. Universidad Piloto de Colombia, 2a edición. Bogotá, Colombia. p42

Secretaría de la Convención de Ramsar. (2013): Manual de Convención de Ramsar, Guía a la Convención sobre los Humedales (Ramsar, Irán, 1971) 6 $6^{\text {a edición. }}$

Segrelles, J.A y Vásquez, J. (2012): Multifuncionalidad rural y nueva ruralidad. La experiencia europea y la potencialidad de Colombia. Ministerio de Agricultura, Alimentación y Medio Ambiente. Secretaría General Técnica. Madrid. p, 364

Zuluaga, F.U., Mejía, E, Valencia R y Arias, A. (2012): Valle del Cauca: procesos históricos. Cali. Manualita S.A. p, 145

\section{Fuentes Electrónicas}

El Espectador. (2016): Los cultivos de caña que amenazan la principal laguna del Valle del Cauca. Edición 20 de enero de 2016. Disponible en: http://www.elespectador.com/noticias/medio-ambiente/los-cultivos-de-cana-amenazan principal-laguna-del-vall-articulo-611505

IGAC: Instituto Geográfico Agustín Codazzi

FAL: FAL Ingenieros S.A Empresa de ingeniería de consulta, especializada en servicios geográficos y geoespaciales 